\title{
Perfil lignoídico del tegumento de semillas de Araucaria angustifolia
}

\author{
Approach on the integument lignin profile of seeds of Araucaria angustifolia
}

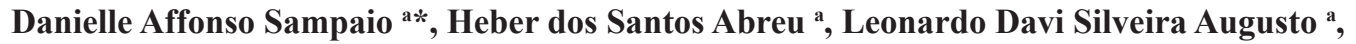 \\ Batista da Silva ${ }^{\text {a }}$, Claudia Marcela Ibanez ${ }^{\text {b }}$ \\ ${ }^{a}$ Universidade Federal Rural do Rio de Janeiro, Instituto de Florestas, Departamento de Produtos Florestais, \\ Río de Janeiro, Brasil, BR 465-KM 07, Seropédica, Río de Janeiro, Brasil, 55-21-26814600, danitheu@gmail.com

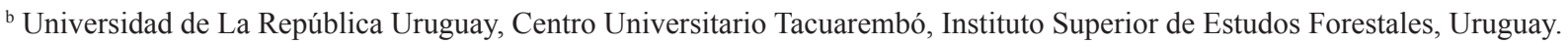

\begin{abstract}
SUMMARY
The aim of this research was to quantify and identify the types of lignin and characterize its functionalization based on apparent physical resistance in each seed coat layers of Araucaria angustifolia. Each seed layer (exotesta, mesotesta and endotesta) was milled, homogenized and pre-extracted with solvents: cyclohexane, ethyl acetate and methanol for quantification of lignin. Pre-treatment with $\mathrm{NaOH} 1 \%$ was also performed in each layer of the seed for lignin quantification and for infrared spectroscopy. The lignin content obtained in the testa was $32.43 \%$ for the three layers. After alkaline treatment, the lignin content was $31.52 \%$ in exotesta, $16.88 \%$ in mesotesta and $15.48 \%$ in endotesta. Dioxane lignin was isolated from the seed coat and reduced with $\mathrm{NaHB}_{4}$. Infrared spectra (FTIR) were obtained from the dioxane lignin, reduced dioxane lignin and alkaline-treated Klason lignin of each layer. Microscopic analyses of the in natura exotesta and mesotesta layers from the seed coat were performed through histochemical test (Wiesner) and fluorescence microscopy. Infrared analyses made possible observation of aldehyde terminations in dioxane lignin and propose the structural profile of Klason lignin in different layers. Fluorescence microscopic analyses allowed identification of highly lignified macrosclereids in exotesta.
\end{abstract}

Key words: lignin, nut, infrared, testa.

\section{RESUMEN}

El objetivo de esta investigación fue identificar y cuantificar los tipos de lignina, y caracterizar su función según la resistencia física aparente de cada capa de la testa de la semilla de Araucaria angustifolia. Cada capa de la semilla (exotesta, mesotesta e endotesta) se molió, homogeneizó y sometió a un ciclo de pre-extracción con solventes (ciclohexano, acetato de etilo y metanol) para preparar el material para cuantificar la lignina. También se realizó en cada capa de la semilla un pre-tratamiento con $\mathrm{NaOH} 1 \%$ para cuantificar la lignina y para aplicar espectroscopía infrarroja. El contenido de lignina en la testa fue 32,43 \% para las tres capas juntas. Después del tratamiento alcalino, el contenido de lignina fue de 31,52 \% en exotesta, 16,88 \% en mesotesta y $15,32 \%$ en endotesta. Lignina dioxano se aisló del tegumento de la semilla y la misma se redujo químicamente con $\mathrm{NaHB}_{4}$. Los espectros infrarrojos se registraron a partir de lignina dioxano, lignina dioxano reducida y de lignina de Klason de cada capa con tratamiento alcalino. Se realizaron análisis microscópicos de las capas de exotesta y mesotesta de la testa de la semilla al natural, por prueba histoquímica (prueba Wiesner) y por microscopía de fluorescencia. El análisis infrarrojo permitió observar la presencia de terminales aldehído en lignina dioxano y trazar el perfil estructural de las ligninas de Klason en capas diferentes. En el análisis microscópico con fluorescencia se identificó en la exotesta la presencia de macroesclereidas altamente lignificadas.

Palabras clave: lignina, piñón, infrarrojo, testa.

\section{INTRODUCCIÓN}

Una gran parte de las semillas forestales en Brasil se ha utilizado en la industria extractiva. Las semillas se pueden utilizar directamente como una fuente de alimento, de proteínas, minerales y aceites, entre otros. Un ejemplo es el uso de semillas de Araucaria angustifolia (Bert.) O. Ktze. para alimentación, que se produce en el sur y sudeste del Brasil (Silva et al. 2014).

Las semillas de $A$. angustifolia han contribuido a la economía local en algunas regiones de Brasil. Datos del
IBGE (2013) informan que en 2013 se vendieron en el país 8.889 toneladas; de estas, 8.608 toneladas fueron comercializada en el sur y 281 toneladas en el sudeste. La semilla del $A$. angustifolia es también conocida como piñón (Conforti y Lupano 2007); ha sido estudiada su germinación (Carvalho 2003) así como su uso en alimentación (Silva et al. 2014). En el primer caso, debido a su corta vida natural y la pérdida total de viabilidad por deshidratación un año después de la cosecha (Carvalho y Nakagawa 2000); en el segundo caso, debido al poder nutricional de la misma (Carvalho 2003, Cordenunsi et al. 2004). Estas semillas 
son sensibles a la reducción del contenido de agua (Eira et al. 1994), lo cual es una característica de las semillas recalcitrantes, un factor que contribuye a la vulnerabilidad de la especie. Cordenunsi et al. (2004) afirman que el color rojizo de la testa de la semilla madura indica la presencia de polifenoles. Sin embargo, hay polifenoles insolubles, tales como la lignina que poseen propiedades que garantizan la estructura celular de la semilla, la protección física y química, así como la conducción de agua.

Debido a la flexibilidad de las enzimas en las plantas, las ligninas pueden ser diferentes en su composición y su contenido. Las que constituyen la madera, conocidas como ligninas tradicionales presentan una composición característica formada por unidades fenilpropano de la serie cumarílica, guaiacílica y siringílica. En las plantas modificadas genéticamente y en otras plantas normales las unidades se han identificado y diferenciado del concepto tradicional (Chen et al. 2013).

Un ejemplo muy reciente ha sido la identificación de lignina rica en ácido cafeíco (lignina-C). Este tipo de lignina se encuentra en alta concentración en la testa de la semilla de la orquídea Vanilla planifolia Jacks. ex Andrews y otras especies tales como Vanilla Pompona Schiede, Vanilla tahitensis Moore, aunque se ha informado de que no todas las semillas monocotiledóneas tienen este tipo de lignina (Chen et al. 2012). El tegumento de las semillas de algunas plantas de la familia de las cactáceas también cuenta con lignina tipo C (Chen et al. 2013). Estas ligninas pueden estar presentes de forma independiente, o coexistir con las ligninas G/S (Guayacil/Siringil), que han sido depositados en los tejidos en las mismas condiciones temporales/espaciales (Tobimatsu et al. 2013). Además se ha registrado, por primera vez, la lignina natural formada por unidades de alcohol-5-hidroxiconiferílico (lignina-5H) en el tegumento de la semilla Escobaria dasyacantha (Engelm.) Britton et Rose (Chen et al. 2012).

El conocimiento de la existencia y el papel de la lignina en algunas semillas es todavía muy incipiente; mientras que la presencia de lignina en las maderas tiene como función principal dar rigidez a la estructura, en las semillas puede tener un papel importante en la regulación del flujo de agua entre el medio interno y externo a través de la testa. Es posible que la relación entre el intercambio de agua de una semilla con la atmósfera esté relacionada con la funcionalidad de la lignina. En este sentido, el objetivo de esta investigación es cuantificar la lignina, caracterizar su función y su solubilidad en $\mathrm{NaOH} 1 \%$ en la testa de semillas de $A$. angustifólia, dada su importancia como fuente de residuos lignocelulósicos.

\section{MÉTODOS}

Preparación del material para análisis. Para comenzar a trabajar con el tegumento de las semillas de A. angustifolia, primero se separaron las almendras de las semillas, utilizando solamente la capa exterior de los piñones (testa) sin el endospermo se utilizó para el análisis químico y histológico. El tegumento de esta semilla comprende: endotesta, mesotesta y exotesta (figura 1). Las capas del tegumento fueron molidas separadamente en un molino de cuchillas tipo Willey después se secaron a temperatura ambiente. Posteriormente, las muestras fueron homogenizadas y sometidas a extracción química. Estas semillas fueron donadas por el Departamento de Silvicultura del Instituto de Bosques de la UFRRJ, pero su origen no fue revelado.

La preparación del material libre de extractivos, se realizó en un extractor de tipo Soxhlet con la siguiente serie eluotrópica de solventes: ciclohexano, acetato de etilo y metanol, por un período de 24 horas sin interrupción para cada solvente (Abreu et al. 2006). Después de cada extracción, los extractos fueron concentrados en un evaporador rotatorio al vacío y en seguida puestos en una cámara para la evaporación completa del solvente. A partir de las muestras libres de extraíbles se iniciaron los análisis.

Lignina de Klason. Para la cuantificación de la lignina de Klason fueron utilizados $300 \mathrm{mg}$ de cada capa procesada secas y libre de extraíbles (exotesta, mesotesta y endotesta) tratadas con ácido sulfúrico $72 \%$ (Abreu et al. 2006).

Tratamiento con $\mathrm{NaOH} 1 \%$. En cada capa procesada libre de extraíbles (exotesta, mesotesta y endotesta) se realizó un tratamiento alcalino. A $2 \mathrm{~g}$ de material seco se añadieron $50 \mathrm{~mL}$ de solución de hidróxido de sodio $1 \%$ y se colocó en baño maría a aproximadamente $90{ }^{\circ} \mathrm{C}$ durante una hora. Luego las muestras se transfirieron a una placa y se lavaron con $100 \mathrm{~mL}$ de agua caliente, después se añadieron $25 \mathrm{~mL}$ de ácido acético al $10 \%$, manteniendo la mezcla durante un minuto. Finalmente, se lavaron las muestras con agua desionizada hasta estar completamente libres de ácido y se colocaron en estufa a $105^{\circ} \mathrm{C}$ hasta peso constante (Abreu et al. 2006). El tratamiento se realizó por triplicado para cada capa. Las muestras tratadas fueron

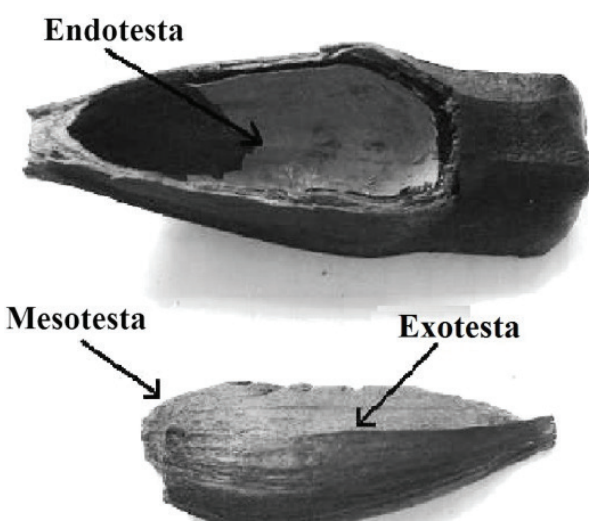

Figura 1. Vista de las capas de tejido de la exotesta, mesotesta y endotesta del tegumento de la semilla de Araucaria angustifolia.

Prospect of the layers of tissue exotesta, mesotesta and endotesta of the seed coat from Arancaria angustifolia. 
utilizadas para la cuantificación de la lignina de Klason y para análisis infrarrojo.

Lignina dioxano. En la preparación de lignina dioxano se utilizaron, aproximadamente $5 \mathrm{~g}$ de muestra seca libre de extractivos, que se colocaron en un matraz aforado de dos salidas, al que se añadió una solución de dioxano y agua $(9: 1)$ con $\mathrm{HCl}$. La mezcla de reacción obtenida se mantuvo bajo calentamiento en un plato caliente en una atmósfera de nitrógeno durante 24 horas. La mezcla de reacción se filtró en un embudo de vidrio sinterizado y se lavó bajo vacío con la misma solución en la que se obtuvo el extracto. Este se concentró en un evaporador rotatorio hasta la aparición de un material viscoso. Este material se precipitó en un gran volumen de agua destilada bajo agitación constante. El precipitado se separó por centrifugación y se lavó bajo vacío con agua destilada y se secó en un desecador a vacío con anhídrido fosfórico (Abreu et al. 2006).

Cuando el espectro infrarrojo indicó la presencia de grupos aldehído terminales, se realizó la reacción de reducción de lignina dioxano usando el reactivo $\mathrm{NaBH}_{4}$. Para esta reacción se disolvieron $70 \mathrm{mg}$ de lignina dioxano en una solución de etanol y $\mathrm{NaOH} 0,1 \mathrm{~N}$ en una atmósfera de nitrógeno.

Espectroscopía infrarrojo. El análisis por espectroscopia infrarroja se efectuó con muestras de lignina de Klason de cada capa tratada con $\mathrm{NaOH} 1 \%$, lignina dioxano y lignina dioxano reducida con $\mathrm{NaBH}_{4}$, usando tableta de $\mathrm{KBr}$ (100 mg de $\mathrm{KBr} /$ material de 1-2 mg) en un espectrómetro (Varian 640-IR espectrómetro FT-IR). Los espectros se registraron en modo experimental de la transmisión por medio de $4 \mathrm{~cm}^{-1}$ de resolución, 128 exploraciones, amplitud espectral entre $4.000-400 \mathrm{~cm}^{-1}$. El análisis por espectroscopía infrarroja se realizó por triplicado para lignina dioxano y lignina dioxano reducida.

Estudio histológico. Parte de los tegumentos de las semillas de A. angustifolia se separaron y fueron puestos en un vaso de Bohemia con agua destilada a ebullición, donde fueron cocidos durante 5 minutos, para facilitar el corte de la testa de la semilla para los análisis histológicos. Los cortes anatómicos transversales del tegumento de las semillas de $A$. angustifolia (exotesta y mesotesta) se hicieron con un escalpelo. Se utilizó la microscopía de campo claro, microscopía fluorescente seguida de la prueba histoquímica de Wiesner (Lin y Dence 1992) para identificar los tejidos lignificados. Los análisis por microscopía de campo claro se realizaron con cortes transversales de la exotesta y mesotesta de la semilla de $A$. angustifolia al natural.

La observación con microscopio de fluorescencia fue realizada con el cubo verde de excitación a 330-385 nm y el filtro FITC (U-MWB2), utilizando el microscópio óptico OLYMPUS BX51 (Barros y Miguens 1998). Se realizó en secciones transversales de la testa de la semilla natural y se tiñeron con reactivo Wiesner, la exotesta y mesotesta.

\section{RESULTADOS}

Caracterización química. El contenido total de lignina que se encontró fue de $32,43 \%$ y representó las capas de tejido juntas (exotesta, mesotesta y endotesta). Este contenido de lignina en el tegumento de las semillas de A. angustifolia fue relativamente alto, en comparación con los niveles reportados para semillas de otras especies arbóreas (cuadro 1).

Los espectros de infrarrojos de la lignina dioxano y lignina dioxano reducida reveló la existencia de una lignina típica de coníferas (G), señal correspondiente $\sim 1.263 \mathrm{~cm}^{-1}$ (Kubo y Kadla 2005). La confirmación de grupos aldehído terminales se realizó con la reacción de reducción del grupo aldehído con $\mathrm{NaBH}_{4}$, cuya señal correspondiente a $1.621-1.690 \mathrm{~cm}^{-1}$ tenía una intensidad muy reducida (parte con trazos) (figura 2).

La intensidad de las señales características de lignina después del tratamiento con $\mathrm{NaOH} 1 \%\left(1.600 \mathrm{~cm}^{-1} \mathrm{y}\right.$ $1.500 \mathrm{~cm}^{-1}$ ) fueron utilizadas para la comparación semicuantitativa. Esta proporción fue 1,30 para la capa exotesta, 1,81 para mesotesta y 2,80 para endotesta (figura 3).

Caracterización histológica. En la observación microscópica, el material natural sin ningún pre-tratamiento histoquímico mostró una capa de células esclereídicas, como

Cuadro 1. Contenido de lignina encontrado en las tres capas de las semillas de Araucaria angustifolia antes y después del tratamiento con $\mathrm{NaOH} 1 \%$.

Lignin found in the three layers of the testa of the Araucaria angustifolia seeds before and after treatment with $\mathrm{NaOH} 1 \%$.

\begin{tabular}{lccc}
\hline \multirow{2}{*}{ Capas } & \multicolumn{2}{c}{ Lignina de Klason (\%) } & \multicolumn{2}{c}{ Diferencia (\%) } \\
\cline { 2 - 4 } & Antes del tratamiento alcalino & Después del tratamiento alcalino & $-1,4$ \\
\hline Exotesta & 30,1 & 31,5 & 13,1 \\
Mesotesta & 29,9 & 16,8 & 22,4 \\
Endotesta & 37,8 & 15,3 & 11,4 \\
Valor medio & 32,6 & 21,2 & \\
\hline
\end{tabular}


un tejido de tono rojizo (figura 4A). La prueba de Wiesner (figura 4B) mostró una coloración roja más intensa, lo que indica la presencia de alta concentración del grupo terminal aldehído, consistente con los resultados obtenidos por análisis de espectrometría.
La observación por microscopía de fluorescencia indicó la presencia de lignina en la capa esclerenquimática (figura 5). La presencia de lignina en las macroesclereidas de la mesotesta y en la región de transición entre exotesta y mesotesta era muy evidente en la fluorescencia.

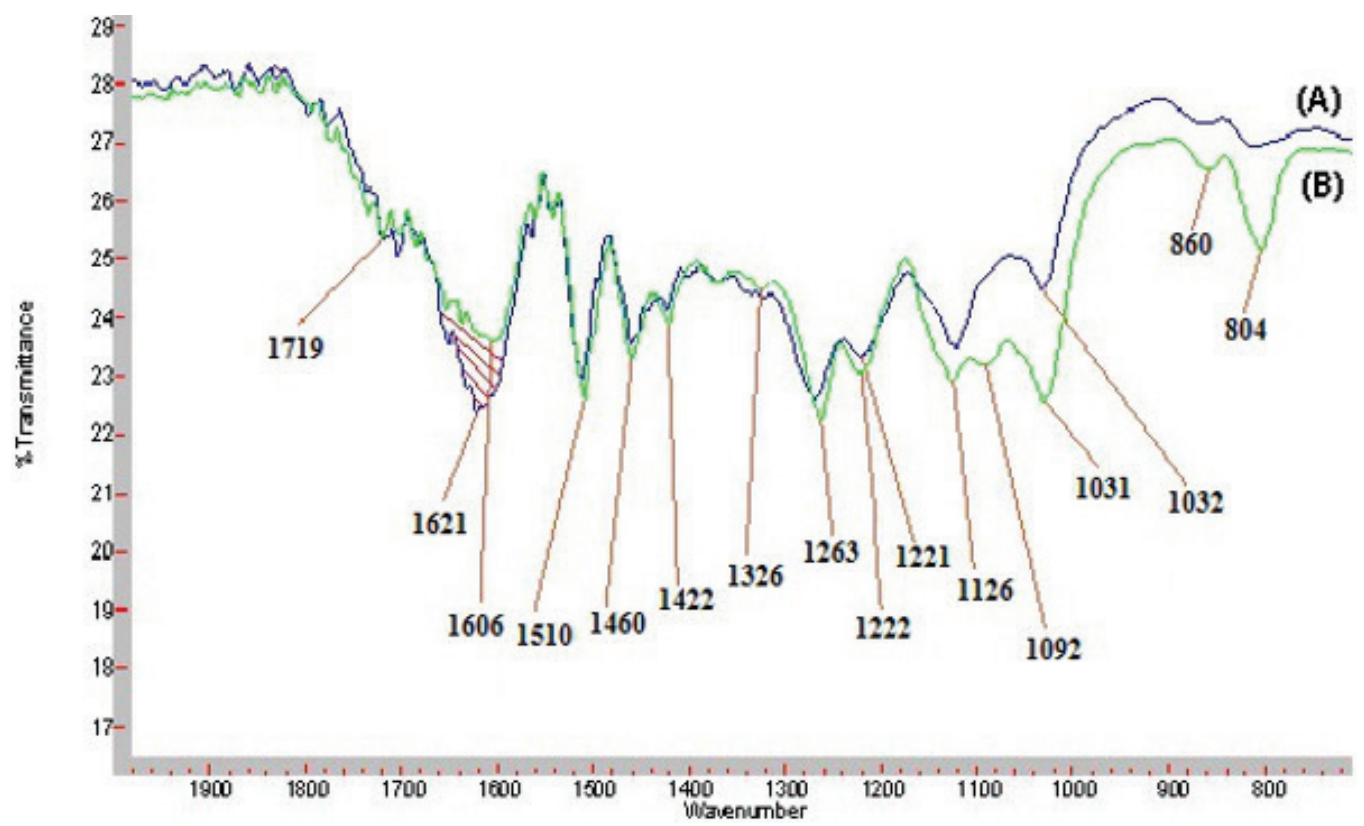

Figura 2. Espectro infrarrojo de lignina dioxano (A) y lignina dioxano reducida con $\mathrm{NaBH}_{4}(\mathrm{~B})$. Infrared spectra of dioxane lignin (A) and dioxane lignin reduced by $\mathrm{NaBH}_{4}(\mathrm{~B})$.

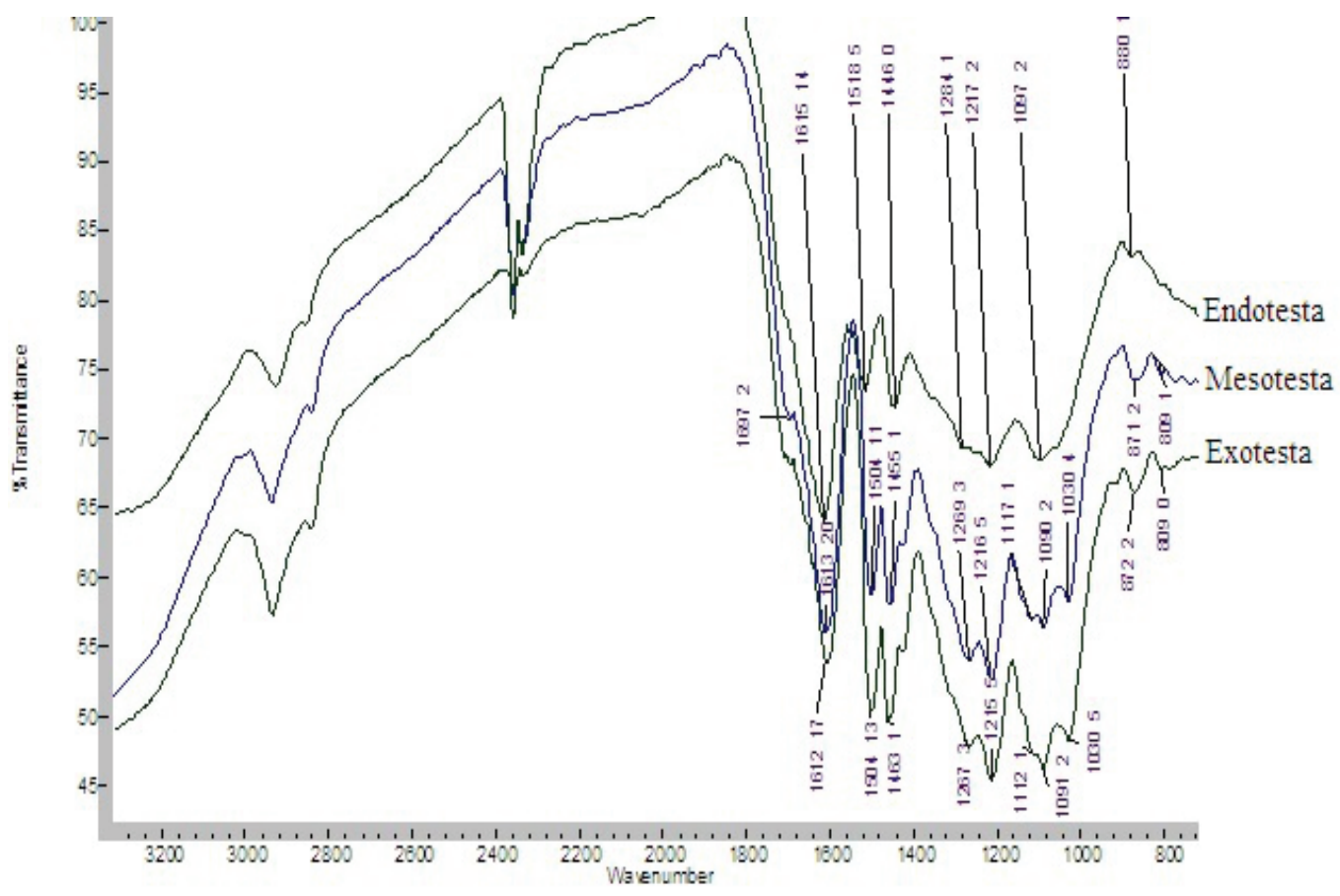

Figura 3. Espectros infrarrojos de la lignina Klason de las capas exotesta, mesotesta y endotesta tratadas con $\mathrm{NaOH} 1 \%$. Spectra in the infrared of the Klason lignin the layers exotesta, mesotesta and endotesta treated with $\mathrm{NaOH} 1 \%$. 

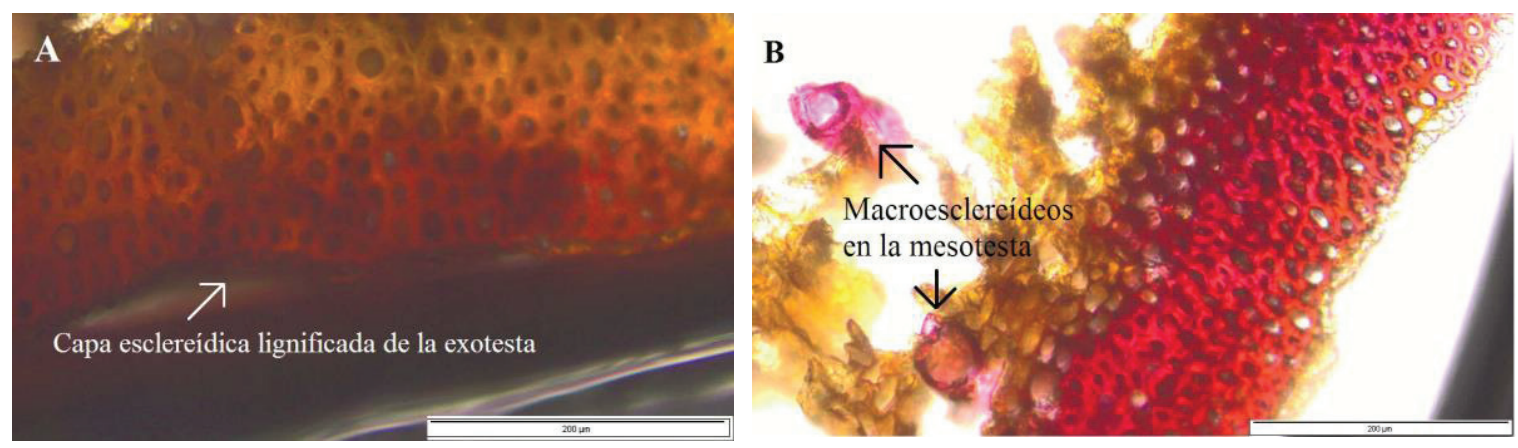

Figura 4. Microfotografía del tegumento de la semilla de Auraucaria angustifolia sin tratar (natural) de exotesta y mesotesta (A) y teñido con reactivo Wiesner $(\mathrm{B})$. reagent stain (B).

Seed coat photomicrography of Auraucaria angustifolia without treatment (natural) from exotesta and mesotesta (A) and under Wiesner

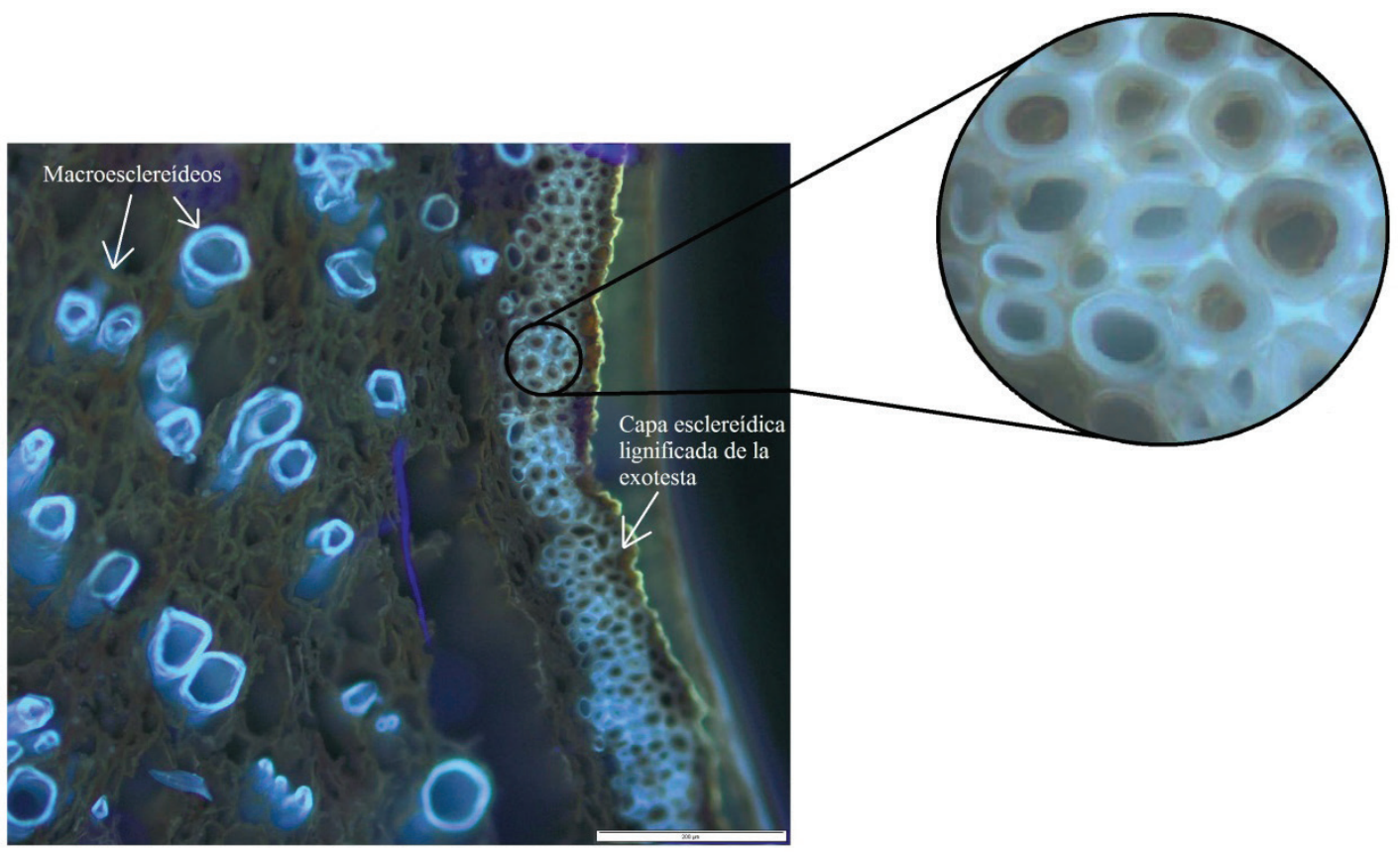

Figura 5. Microfotografía que muestra autofluorescencia bajo filtro de excitación verde (330-385 nm) de la testa de la semilla natural de Araucaria angustifolia. caria angustifolia.

Photomicrography showing autofluorescence under green excitation filter (330-385 nm) from natural cross-section from seed coat of Arau-

\section{DISCUSIÓN}

El alto teor de lignina de $32,43 \%$ obtenido de la testa de la semilla puede ser comparable a los encontrados en el bagazo de la caña de azúcar, madera, etc., puesto que la propia madera Araucaria angustifolia tiene un contenido de lignina de alrededor de $28 \%$ (Mattos 2006).

En los espectros de infrarrojos de la lignina dioxano y lignina dioxano reducida (figura 2), la señal en $1.263 \mathrm{~cm}^{-1}$ registrada de la lignina dioxano fue asignada a la vibración del anillo aromático de unidades guaiacílicas con contribución del estiramiento $\mathrm{C}=\mathrm{O}$ (Lin y Dence 1992). Se obser- varon señales de grupo éster a $1.700-1.720 \mathrm{~cm}^{-1}(\mathrm{vC}=\mathrm{O})$. Una fuerte señal fue observada a $1.606-1.660 \mathrm{~cm}^{-1}$ asignada a las extensiones de carbonilo de aldehído y/o cetona conjugados. La ocurrencia de la señal a $1.221 \mathrm{~cm}^{-1}$ presupone la existencia de una alta concentración de enlaces $\mathrm{C}-\mathrm{C}$ atribuidos a la presencia de estructuras condensadas (Lin y Dence 1992). Se observo también que hubo un incremento de las intensidades de las señales entre $1.126-1.031 \mathrm{~cm}^{-1}$ característica del aumento de estiramiento $\mathrm{vC}-\mathrm{OH}$.

La presencia de grupos funcionales aldehídos en la lignina (lignina ${ }_{\mathrm{ALD}}$ ), como se observa en lo mismo espectro infrarrojo (figura 2), puede contribuir a la rápida deshi- 
dratación de la semilla y su baja degradabilidad, mientras que las ligninas aldehídicas son más hidrófobicas que las ligninas comunes (Ralph et al. 2001). Bhinu et al. (2009) cambiaron la vía metabólica de la lignina en la semilla de Brassica napus L. (canola) y llevó a la formación de lignina con una mayor concentración de grupos aldehídos.

Los espectros infrarrojos registrados para la lignina de Klason de las respectivas capas tratadas con $\mathrm{NaOH}$ $1 \%$ (figura 3) mostraron señales características de lignina $\left(1.600 \mathrm{~cm}^{-1}\right.$ y $\left.1.500 \mathrm{~cm}^{-1}\right)$. La señal en $1.500 \mathrm{~cm}^{-1}$ se ha atribuido a la vibración del anillo aromático siendo la misma considerada un modelo interno para la normalización de los espectros, al no modificar los sustituyentes en el anillo aromático y la señal alrededor de $1.600 \mathrm{~cm}^{-1}$ se le ha asignado enlaces de vibración aromática con estiramiento $\mathrm{C}=\mathrm{O}, \mathrm{S}>\mathrm{G}, \mathrm{G}$ condensado $>$ eterificado (Lin y Dence 1992).

El contenido de lignina Klason encontrados en diferentes capas de la testa fue del orden de $31,89 \%$ en exotesta, $29,90 \%$ en mesotesta y $38,58 \%$ en endotesta (cuadro 1 ). Aunque la lignina Klason es un método ampliamente utilizado para la determinación del porcentaje de lignina en materiales lignocelulósicos (Chen et al. 2012), la misma puede presentar un valor sobreestimado del contenido de lignina debido a la presencia de polisacáridos y proteínas no extraídos que puede medirse junto (Hatfield y Fukushima 2005). Esto podría explicar el alto contenido de lignina Klason para la endotesta.

Las diferencias de la lignina (cuadro 1) (figura 3) de las capas muestran una disminución significativa de la exotesta a la endotesta después del tratamiento alcalino. Esta pérdida de la lignina de la mesotesta a la endotesta, puede ser debida a una mayor cantidad de ligninas con $\mathrm{OH}$ libres en el mesotesta y endotesta, o a la presencia de complejo lignina-carbohidrato (LC) (Jeffries 1990) o fenoles en conectividad lignina-pared celular refiriéndose a las llamadas áreas "core" y "no core lignin" (Weng y Chapple 2010, Jayabal et al. 2012).

Dado que las señales en el infrarrojo (figura 3) representan la proporcionalidad de los grupos funcionales en las muestras, este hecho se utiliza para inferir la presencia y frecuencia de las subestructuras que componen las ligninas. Los espectros infrarrojos registrados en maderas tropicales muestran que la señal en $1.600 \mathrm{~cm}^{-1}$ tiene tres componentes. La señal de intensidad más alta corresponde a la vibración de los anillos aromáticos de las subestructuras $\beta$-O-4 y señales de intensidades de vibración más bajos corresponde a los anillos aromáticos de las subestructuras $\beta-\beta$ e $\beta-5$ (Lin y Dence 1992). Con base en este hallazgo, la razón de intensidad de las señales a $1.600 \mathrm{~cm}^{-1}$ y $1.500 \mathrm{~cm}^{-1}$, hacen suponer que la lignina de la exotesta tiene un perfil estructural expresado por la naturaleza condensada, mientras que el perfil de lignina presente en las otras capas presenta menores grados de condensación. Esto puede hacer que la capa interna (mesotesta y endotesta) sufra mayores niveles de degradación que la exotesta, que actúa como una barrera de protección física y química en las semillas contra factores bióticos y abióticos del medio ambiente (Wada et al. 2011).

Las ligninas del Pterophyta, Gimnospermas y Monocotiledóneas mantienen una cierta proporción del grupos $\rho$ - hidroxifenila, la cual cae a niveles insignificantes en dicotiledóneas. La relación de los grupos guayacil-siringil se produce en 99:1 en Pterophytas, se eleva en 1:1 en Gimnospermas, y luego llega a 1: 4 en las Angiospermas. De manera significativa, las ligninas de los géneros Welwitschia, Gnetum y Ephedra, del grupo gimnospérmico más reciente, Gnetatae, tienen proporciones guayacil-siringil de 1:1 a 1:3, asemejándose así a la composición de las ligninas angiospémicas (Gottlieb et al. 1996).

Los tejidos mostraron un tinte marcadamente rojizo en comparación con el tejido original después de la prueba Wiesner. Incluso la síntesis de DHP con el coniferaldehido produjo un precipitado de tono rojizo (Baucher et al. 1996) en consonancia con lo percibido. En plantas modificadas genéticamente pueden ser más evidente este tipo de lignina puesto que desactivar la enzima CAD (cinamil alcohol deshidrogenasa) en plantas transgénicas conduce a la acumulación de lignina aldehído. Esta enzima funciona en el paso final de la reducción enzimática de cumaraldehído, coniferaldehído y sinapaldehído en los respectivos alcoholes durante la formación de la lignina (Ralph et al. 2001).

\section{CONCLUSIONES}

Los resultados de la cuantificación y del análisis por espectroscopia infrarroja permiten proponer que el tegumento de las semillas de A. angustifolia contiene altos niveles de lignina tipo guaiacílica $(\mathrm{G})$ rica en una estructura condensada de alta complejidad estructural. El análisis también permite observar la presencia de grandes cantidades de grupos terminales aldehídos, lo que significa una baja actividad de la enzima CAD en la semilla. En cuanto a la estructura anatómica de la exotesta de la semilla, constituye un material con una estructura altamente lignificada.

\section{REFERENCIAS}

Abreu HS, AM Carvalho, MBO Monteiro, RPW Pereira, HR Silva, KCA Souza, KF Amparado, DB Chalita. 2006. Métodos de análise em química da madeira. Rio de Janeiro, Brasil. Floresta e Ambiente. 20 p.

Barros CF, FC Miguens. 1998. Ultrastructure of the epidermal cells of Beilshmiedia rigida (Mez) Kosterm (Lauraceae). Acta Microscopica 6(3):451-461.

Baucher M, B Chabbert, G Pilate, JV Doorsselaere, MT Tollier, M Petit-Conil, D Cornu, B Monties, MV Montagu, D Inzé, L Jouanin, W Boerjan. 1996. Red xylem and higher lignin Extractability by down-regulating a cinnamyl alcohol dehydrogenase in poplar. Plant Physiology 112: 1479-1490.

Bhinu VS, LI Rong, J Huang, S Kaminskyj, A Sharpe, A Hannoufa. 2009. Perturbation of lignin biosynthesis pathway in Brassica napus (canola) plants using RNAi. Canadian Journal of Plant Science 3(89):441-453. 
Carvalho NM, J Nakagawa. 2000. Sementes: ciência, tecnologia e produção. São Paulo, Brasil. Jaboticabal. 588 p.

Carvalho PER. 2003. Espécies florestais brasileiras. Brasilia, Brasil. Embrapa. 1038 p.

Chen F, Y Tobimatsu, D Dhavkin-Frenkeld, RA Dixona, J Ralphc. 2012. A polymer of caffeyl alcohol in plant seeds. PNAS 109(5):1772-1777.

Chen F, Y Tobimatsu, L Jackson, J Ralph, RA Dixon. 2013. Novel seed coat lignins in the Cactaceae: structure, distribution and implications for the evolution of lignin diversity. The Plant Journal 73(2): 201-211.

Conforti PA, CE Lupano 2007. Starch characterization of Araucaria angustifolia and Araucaria araucana seeds. StarchStarke 59:284-289.

Cordenunsi BR, EW De Menezes, MI Genovese, C Colli, AGA De Souza, FM Lajolo. 2004. Chemical composition and glycemic index of Brasilian pine (Araucaria angustifolia) seeds. Journal of agricultural land Food Chemistry 52: 3412-3416.

Eira MTS, AN Salomão, R Cunha, DK Carrara, CMC Mello. 1994. Efeito do teor de água sobre a germinação de sementes de Araucaria angustifolia (Bert.) O. Ktze.- Araucariaceae. Revista Brasileira de Sementes 16(1):71-75.

Gottlieb OR, Kaplan MAC, Borin MRMB. 1996. Biodiversidade: um enfoque químico-biológico. Rio de janeiro, Brasil. UFRJ. 268 p.

Halfield R, Fukushima RS. 2005. Can lignina be accurately mersured? Crop Science 45:832-839.

IBGE (Instituto Brasileiro de Geografia e Estatística, BR). 2013. Produção da Extração Vegetal e da Silvicultura. Consultado 15 abr. 2015. Disponible en http://www.sidra.ibge.gov.br/ bda/tabela/listabl.asp

Jayabal S, S Sathiyamurthy, KT Loganathan, S Kalyanasun- daram. 2012. Effect of soaking time and concentration of $\mathrm{NaOH}$ solution on mechanical properties of coir-polyester composite. Bulletin of Materials Science 35(4): 567-574.

Jeffries TW. 1990. Biodegradation of lignin-carbohydrate complexes. Biodegradation 1:163-176.

Kubo S, JF Kadla. 2005. Hydrogen Bonding in Lignin: A Fourier Transform Infrared Model Compound Study. Biomacromolecules 6: 2815-2821.

Lin SY, CW Dence. 1992. Methods in lignin chemistry. Berlín, Alemania. Spring-Verlag, $568 \mathrm{p}$.

Mattos PP, CD Bortoli, R Marchesan. 2006. Caracterização Física, Química e Anatômica da Madeira de Araucaria angustifolia (Bert.) O. Kuntze. 4 p. (Comunicado Técnico 160).

Ralph J, C Lapierre, JM Marita, H Kim, RD Hatfielda, S Ralph, C Chapple, R Franke, JV Doorsselaere, RR Sederoff, DM O'Malley, JJ Mackay, N Yahiaoui, AM Boudet, MG Pilatek, L Jouanin, W Boerjan. 2001. Elucidation of new structures in lignins of CAD COMT-deficient plants by NMR. Phytochemistry 57:993-1003.

Silva SM, EA Koehnlein, A Bracht, R Castoldi, GR Morais, ML Baesso, RA Peralta, CGM Souza, AB Sá-Nakanishi, RM Peralta. 2014. Inhibition of salivar and pancreatic $\alpha$ - amylases by a pinhão coat (Araucaria angustifolia) extract rich in condensed tannin. Food Research International 56:1-8.

Tobimatsu Y, J Nakashima, LL Escamilla-Treviño, L Jackson, RA Dixon, J Ralph. Coexistence but Independent Biosynthesis of Catechyl and Guaiacyl/Syringyl Lignin Polymers in Seed Coats. The Plant Cell 25:2587-2600.

Wada S, JA Kennedy, BM Reed. 2011. Seed-coat anatomy and proanthocyanidins contribute to the dormancy of Rubus seed. Scientia Horticulturae 130:762-768.

Weng JK, C Chapple. 2010. The origin and evolution of lignin biosynthesis. New Phytologist 187 (2): 273-285.

Recibido: 24.02 .16

Aceptado: 29.06.16 
